\title{
N90, a Diversity Index Sensitive to Variations in Beta Diversity Components
}

\author{
M. Teresa Farriols*(D), Francesc Ordines (D) and Enric Massutí \\ Centre Oceanogràfic de les Balears, Instituto Español de Oceanografía, Moll de Ponent s/n, 07015 Palma, Spain; \\ xisco.ordinas@ieo.es (F.O.); enric.massuti@ieo.es (E.M.) \\ * Correspondence: mt.farriols@ieo.es
}

Citation: Farriols, M.T.; Ordines, F.; Massutí, E. N90, a Diversity Index Sensitive to Variations in Beta Diversity Components. Diversity 2021, 13, 489. https://doi.org/10.3390/ d13100489

Academic Editor: Michael Wink

Received: 31 August 2021

Accepted: 30 September 2021

Published: 6 October 2021

Publisher's Note: MDPI stays neutral with regard to jurisdictional claims in published maps and institutional affiliations.

Copyright: (c) 2021 by the authors. Licensee MDPI, Basel, Switzerland. This article is an open access article distributed under the terms and conditions of the Creative Commons Attribution (CC BY) license (https:/ / creativecommons.org/licenses/by/ $4.0 /)$.

\begin{abstract}
Species diversity in a community is mainly related to the number and abundance of species that form it. $N_{90}$ is a recently developed diversity index based on the results of the similarity percentage (SIMPER) analysis that represents the number of species contributing up to ninety percent of within-group similarity in a group of samples. The calculation of $N_{90}$ is based on the Bray-Curtis similarity index and involves the number of species and abundances in a group of samples. We have explored the properties of $N_{90}$ compared to other alpha, beta and gamma diversity indices and to beta diversity measures accounting for nestedness and turnover. We have used a non-real data set to compare the values of all indices with $N_{90}$ and two real data sets of demersal fish communities along large and short depth gradients with higher influence of turnover and nestedness, respectively, to correlate the same indices with $N_{90}$. The sensitivity of $N_{90}$ to reductions in the frequency of occurrence and the evenness of the distribution of species abundances among samples allows the detection of diversity loss due to the fishing-induced retreatment of species populations to localities presenting the most favorable ecological conditions. This property, both in the identification of species replacement and species loss through SIMPER analysis, make $N_{90}$ a useful indicator to support the Ecosystem Approach to Fisheries within the current context of global change.
\end{abstract}

Keywords: beta diversity; similarity; species richness; species replacement; species loss; turnover; nestedness

\section{Introduction}

Diversity is a founding, but at the same time, complex concept in ecology. More than species diversity in the community, understood as a group of interdependent organisms of different species growing or living together in a specified habitat, diversity can be related to genetic diversity within populations or diversity of functional traits. However, for most ecologists, diversity has to do with the number and abundance of species in the community, and a lot of attempts have been made to express this concept numerically. Because of this, a high number of diversity indices have been proposed showing different aspects of the community structure, taking into account factors ranging from the number of species and the relative abundance or biomass of these species, to the taxonomic or functional relationships between them [1]. Although it is generally agreed that diversity is a multidimensional concept and that the use of diversity indices depends on what effect on diversity you want to detect, there is no consensus about the indices that should be used in each case. However, traditional or classical diversity indices such as Species Richness (S), Shannon $\left(H^{\prime}\right)$ or Pielou's evenness $\left(J^{\prime}\right)$, are usually chosen to describe biological communities because, at least, they are easy to calculate and allow comparisons with previous works. Although in recent years, a new family of diversity indices, known as Hill numbers, have been preferred because they have shown more desired properties than the raw form [2,3]; for example, they obey an intuitive replication principle or doubling property and they are all expressed in units of effective numbers of species [4]. 
Taking into account changes of diversity along transects or across environmental gradients, the concept of beta diversity emerges. Although there is some controversy $[5,6]$, it is generally agreed that beta diversity measures the species that change between samples or sites composing a community, mainly due to species replacement or species loss [7]. The concept of beta diversity was originally proposed by Whittaker $[8,9]$, and their measures were summarized by Chao and Chiu [10] in two major approaches: (i) the diversity decomposition approach that consists of decomposing the total diversity (gamma) into its within-community component (alpha) and between-community component (beta), which can be applied to species richness as well as to other diversity indices involving abundances in their calculations; and (ii) the variance framework approach that includes various factors from clustering or ordination analysis to dissimilarity measures between pairs of sites (e.g., [5,11,12]) to compute beta diversity. Moreover, dissimilarity indices allow the distinction of species loss (or nestedness) and species replacement (or turnover) components of beta diversity and can be extended to multiple-site measures [7].

$N_{90}$ is a diversity index developed by Farriols et al. [13], based on the results of the Similarity Percentage (SIMPER) analysis [14]. This analysis takes into account the similarity in species composition between pairs of samples of a group to calculate the average similarity within the group (or within-group similarity). The $N_{90}$ index represents the number of species contributing up to the $90 \%$ of within-group similarity in a group of samples, based on the calculation of the contribution of each species. Like SIMPER analysis $N_{90}$ uses the Bray-Curtis similarity index as proposed by Clarke [14]. Following the variance framework, within-group similarity could be interpreted as an inverse measure of beta diversity. The hypothesis behind the $N_{90}$ index is that impacted communities may see both the frequency of occurrence and the evenness of the distribution of species abundances reduced among samples. This leads to a decrease in $N_{90}$ due to the retreat of species populations to the localities presenting the most favorable ecological conditions.

The aim of this work is to explore the properties of $N_{90}$ compared to other diversity indices involving number of species and abundance in their calculation. To do so we compared $N_{90}$ to classical diversity indices and their alpha, gamma and beta versions. Following the variance framework approach, we have also compared $N_{90}$ to beta diversity measures accounting for nestedness and turnover and to within-group similarity from SIMPER analysis. We have used a non-real data set with several groups of samples showing different values of abundance distributions and number of species between samples to compare the values of all indices with $N_{90}$. We have also used two real data sets of demersal fish communities along large and short depth gradients with higher influence of turnover and nestedness, respectively, to correlate the same indices with $N_{90}$.

\section{Materials and Methods}

\subsection{Background Calculation}

The $N_{90}$ is based on the SIMPER analysis that quantifies the contribution of each species to the within-group similarity in a group of samples. This analysis starts with the calculation of the Bray-Curtis similarity index [15] as proposed by Clarke [14]:

$$
S_{j k}(i)=100 * \frac{2 * \min \left(y_{i j}, y_{i k}\right)}{\sum_{i=1}^{p}\left(y_{i j}+y_{i k}\right)}
$$

where $y_{i j}$ is the abundance of the species $i$ in the sample $j ; y_{i k}$ is the abundance of the species $i$ in the sample $k ; p$ is the total number of species in $j$ and $k$; and $\min \left(y_{i j}, y_{i k}\right)$ is the minimum value of the abundance of species $i$ between the samples $j$ and $k$, taking zero into account. The contribution of each species $i$ to the total similarity of the group $S_{i}$ is the mean value 
of $S_{j k}(i)$ for a species in all the sample comparisons in the group. As a result, the total similarity in a group (Sim) is the sum of $S_{i}$ for all the species in the group:

$$
\operatorname{Sim}=\sum_{i=1}^{p} S_{i}
$$

Then the contribution of $\mathrm{Si}$ to $\mathrm{Sim}$ is rescaled to $100 \%$ and the species are arranged in decreasing order.

\section{2. $N_{90}$ Index}

The $N_{90}$ index is based on the SIMPER analysis and the calculations already explained in Section 2.1. Once the contribution of $S_{\mathrm{i}}$ to $\operatorname{Sim}$ is rescaled to $100 \%$ and the species are arranged in decreasing order, the number of species that contributes up to $90 \%$ of within-group similarity is obtained ( $n_{90}$; Figure 1$)$.

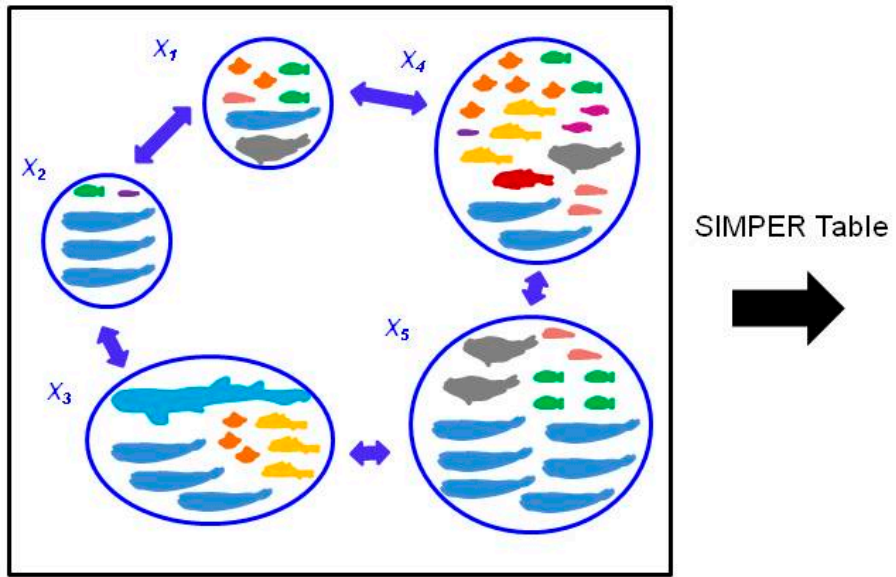

\begin{tabular}{|c|c|c|c|c|}
\hline Species & $\mathrm{A}$ & $S_{\mathrm{i}}$ & $\% \mathrm{C}$ & $\Sigma$ \\
\hline & 3 & 18 & 45 & 45 \\
\hline & 1.8 & 8 & 20 & 65 \\
\hline & 2 & 6 & 15 & 80 \\
\hline & 1 & 3 & 7 & 87 \\
\hline & 0.8 & 2 & 5 & $\mathbf{9 2}$ \\
\hline
\end{tabular}

Figure 1. Calculation of number of species contributing to $90 \%$ similarity from SIMPER analysis in a group with 5 samples $\left(n_{90}\right)$. SIMPER table associated with $n_{90}$ is also presented, where $A$ is the average abundance of each species in the group; $S_{i}$ is the contribution of each species to within-group similarity; \%C is the percentage contribution of each species to within-group similarity; and $\Sigma$ is the cumulative percentage contribution. Intra-group similarity for this example was Sim $=40.8$.

This procedure is done for each re-sampling in a jack-knife routine, which removes a sample each time, in order to obtain the average and the dispersion value for the group of samples analyzed. At the end of the procedure, there are as many lists of contribution to similarity by species as number of re-samplings. The $N_{90}$ diversity index is the mean number of species which accumulates up to $90 \%$ of within-group similarity in all the re-samplings (mean $n_{90}$; Figure 2). In Appendix A we introduce the script developed to calculate $N_{90}$ in R, version 4.4.1 [16], and the use of the script and their main functions are explained. Vegan package [17] is required to carry out all the analyses. 


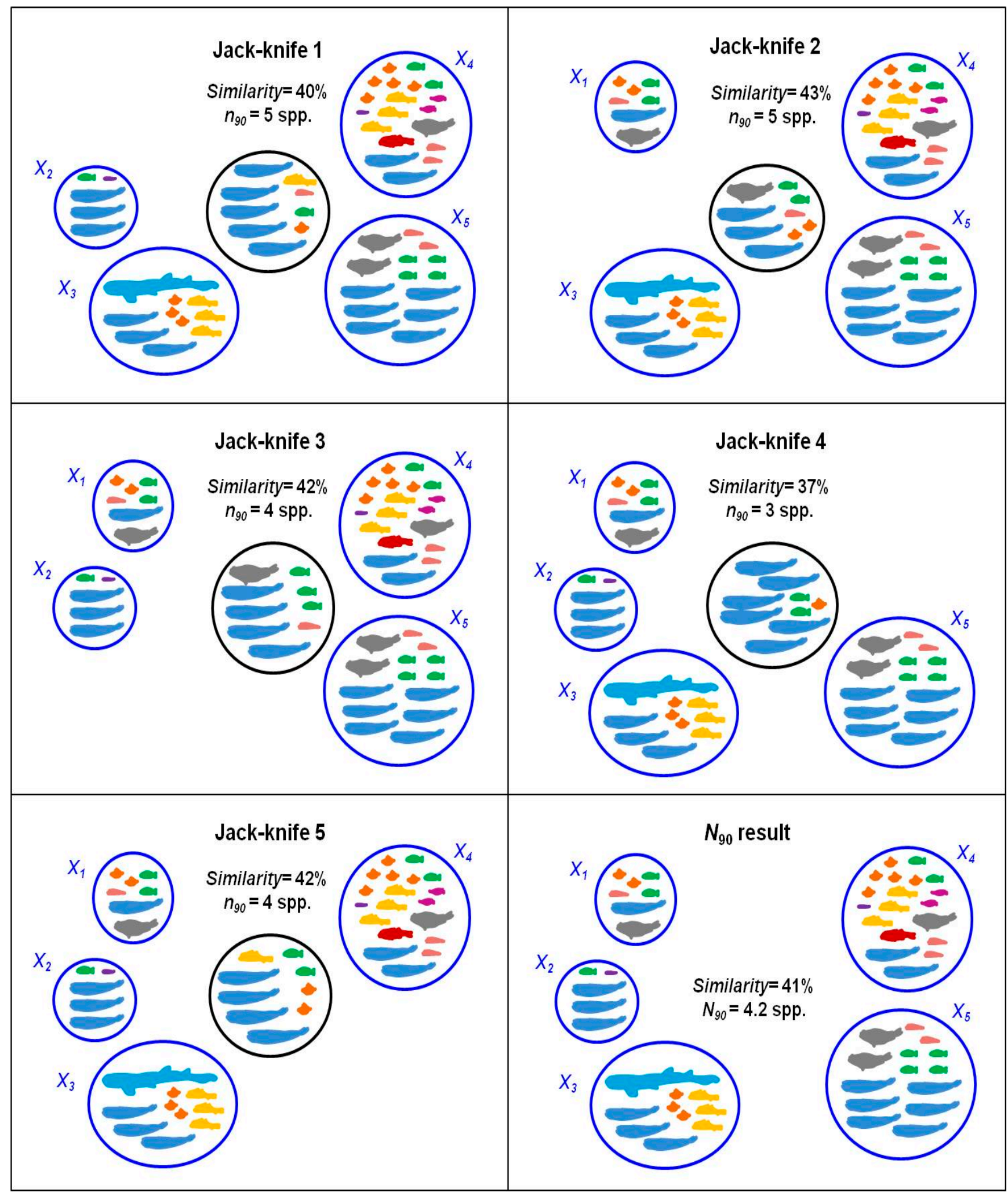

Figure 2. Jack-knifes for the calculation of $N_{90}$ in a group with 5 samples. In each Jack-knife a single sample is removed from the group and the number of samples contributing up to $90 \%$ to within-group similarity $\left(n_{90}\right)$ and the total similarity of the group is calculated. $N_{90}$ is the mean value of $n_{90}$ obtained from all the re-samplings. 


\subsection{Diversity Decomposition Approach}

Following the multiplicative partitioning approach [6], alpha, beta and gamma versions of $S, H^{\prime}$, Hill number of order $1\left(H_{1}\right), J^{\prime}$ and $J_{1}$ were calculated to frame $N_{90}$ in alpha, beta or gamma components of diversity. $S$ is the raw number of species in each haul and $H^{\prime}, H_{1}, J^{\prime}$ and $J_{1}$ were calculated as follows:

$$
\begin{gathered}
H \prime=-\sum_{\mathrm{i}=1}^{\mathrm{S}} p_{\mathrm{i}} \operatorname{Ln} p_{\mathrm{i}} \\
H_{1}=\exp H^{\prime} \\
J^{\prime}=\frac{H^{\prime}}{\mathrm{LnS}} \\
J_{1}=\frac{H_{1}}{\mathrm{~S}}
\end{gathered}
$$

where $p_{\mathrm{i}}$ is the proportion of all individuals belonging to species $i$ and $S$ is the total number of species in the sample.

In the case of $S:$ (i) alpha diversity was calculated as the mean number of species among the samples of each group; (ii) gamma diversity was calculated as the total number of species for the whole group; and (iii) beta diversity was calculated as gamma diversity divided by alpha diversity. Similarly, alpha, beta and gamma versions of $H^{\prime}, H_{1}, J^{\prime}$ and $J_{1}$ were calculated: (i) alpha diversity was calculated as the mean value of each index among all the samples in each group; (ii) gamma diversity was calculated from the mean values of abundances for each species in the group of samples and then calculation of each diversity index for the whole group; and (iii) beta diversity was calculated as gamma diversity divided by alpha diversity.

Once all the indices were calculated, we correlated the values of $N_{90}$ to alpha, beta and gamma versions of $S, H^{\prime}, H_{1}, J^{\prime}$ and $J_{1}$ by means of linear regression analysis.

\subsection{Variance Framework Approach}

We have calculated three multiple-site beta diversity measures. These measures are derived from the pair-wise dissimilarity indices of Sørensen [18,19], Simpson [19-21] and nestedness [7]. They have been chosen because, like their pair-wise analogs, they are able to distinguish the main causes of change in beta diversity: species replacement or turnover and species loss or nestedness between sites of a community. While the Sorensenbased multiple site dissimilarity index ( $\left.\beta_{S O R}\right)$ [7] accounts for both species turnover and nestedness, the Simpson-based multiple site dissimilarity $\left(\beta_{\text {SIM }}\right)$ [7] only accounts for species turnover. The multiple-site dissimilarity measure of nestedness $\left(\beta_{N E S}\right)$ [7] is derived from simple subtraction as follows:

$$
\begin{gathered}
\beta_{S O R}=\frac{\left[\sum_{i<j} \min \left(b_{i j}, b_{j i}\right)\right]+\left[\sum_{i<j} \max \left(b_{i j}, b_{j i}\right)\right]}{2\left[\sum_{i} S_{i}-S_{T}\right]+\left[\sum_{i<j} \min \left(b_{i j}, b_{j i}\right)\right]+\left[\sum_{i<j} \max \left(b_{i j}, b_{j i}\right)\right]} \\
\beta_{S I M}=\frac{\left[\sum_{i<j} \min \left(b_{i j}, b_{j i}\right)\right]}{\left[\sum_{i} S_{i}-S_{T}\right]+\left[\sum_{i<j} \min \left(b_{i j}, b_{j i}\right)\right]} \\
\beta_{\text {NES }}=\beta_{S O R}-\beta_{S I M}
\end{gathered}
$$

where $S_{i}$ is the total number of species in a site $i ; S_{\mathrm{T}}$ is the total number of species considered in all sites together; and $b_{i j}, b_{j i}$ are the number of species exclusive to site $i$ and $j$, respectively. All the indices were calculated in R, version 4.4.1 [16], with functions developed by Baselga [7].

Within-group similarity has also been included in the analysis as an inverse measure of beta diversity, because, like $N_{90}$, it includes abundances of species in its calculation (see Section 2.1). 
When all the indices were calculated, and due to the non-constant variance of residuals, we assessed the correlation of the values of $N_{90}$ with all the indices from Sections 2.3 and 2.4 through the Spearman's rank correlation coefficient $(\rho)$.

\subsection{Non-Real Data Set}

A non-real data set available in the Supplementary Materials data was used to explore the properties of $N_{90}$. The data set is in two files ('nonreal_sp.csv' and 'nonreal_group.csv') and its use is analogous to the data set used as an example in Appendix A. The 12 groups of samples created (A-L) take into account changes in abundance distributions and number of species between samples. All the groups contain 10 samples. Abundances of species are 10 in all cases, except when it is indicated in the group, and are distributed as follows:

- Group A: Maximum similarity; 20 species equally abundant in all samples with abundance of 10 .

- Group B: Maximum similarity and lower abundance than group A; 20 species equally abundant in all samples with abundance of 5 .

- Group C: Disappearance of $50 \%$ of abundance of $50 \%$ of species in all samples; 10 species are equally abundant in all samples with an abundance of 10 and 10 species are equally abundant in all samples with an abundance of 5 .

- Group D: Disappearance of 50\% of species in all samples; 10 species are equally abundant in all samples with an abundance of 10 and 10 species have disappeared from all samples.

- Group E: Reduction of 50\% in abundance of all species in 50\% of samples; All species are equally abundant in 5 samples with an abundance of 5 and in 5 samples with an abundance of 10 .

- Group F: Disappearance of $25 \%$ of species from all samples and reduction of $50 \%$ of abundance in $25 \%$ of species; 10 species are equally abundant in all samples with an abundance of 10, 5 species are equally abundant in all samples with an abundance of 5 and 5 species have disappeared from all samples.

- Group G: Each sample presents a subset of species of the previous one, with abundances of 10 .

- Group H: Each sample presents a subset of species of the previous one, with abundances of 10, but with a higher number of species than in group G.

- Group I: There is species loss and replacement between samples, with abundances of 10

- Group J: There is lower species loss and replacement between samples than group I, with abundances of 10 .

- Group K: Same species loss and replacement between samples as J, with abundances of 5 in some samples.

- Group L: Higher species loss and lower replacement of species between samples than group J.

All the indices from Sections 2.3 and 2.4 have also been calculated for all the groups of samples to compare the results with $N_{90}$.

\subsection{Real Data Set}

Data collected during the International Bottom Trawl Survey in the Mediterranean (MEDITS) on demersal fish communities of the Balearic Islands was used to correlate $N_{90}$ with diversity indices from Sections 2.3 and 2.4. The characteristics of the sampling gear and protocols are explained in detail by Spedicato et al. [22]. This scientific survey has been conducted annually since 2001 during late spring in the Balearic Islands, covering the soft bottoms of the continental shelf and slope between 50 and $800 \mathrm{~m}$ depth. According to the MEDITS protocol, four depth strata were taken into account: (i) shallow shelf from 50 to $100 \mathrm{~m}$; (ii) deep shelf from 101 to $200 \mathrm{~m}$; (iii) upper slope from 201 to $500 \mathrm{~m}$; and (iv) middle slope from 501 to $800 \mathrm{~m}$. A total of 650 hauls (around 50 per year) carried out between 2002 and 2015 were analyzed. In each haul, fish species were sorted and individuals were 
counted and weighed. Abundances of fish species were standardized to one square $\mathrm{km}$, using the horizontal opening of the net and the distance covered in each haul, obtained using the SCANMAR system and Global Positioning System (GPS), respectively. Markedly pelagic or mesopelagic species were excluded from the analysis.

The groups of samples considered for the calculation of all the indices, including $N_{90}$, were defined by the MEDITS depth strata and the sampling year. Depth is a factor that highly structures demersal fish communities, with a high grade of species replacement along a depth gradient. As such, a high influence of turnover is expected when considering long depth gradients, like the four depth strata sampled during MEDITS surveys $(50-800 \mathrm{~m})$. Therefore, we have also restricted the analysis to the stratum showing higher values of nestedness $\left(\beta_{N E S}\right)$ to consider shorter depth gradients less influenced by turnover than larger ones. In this case, a homogeneous community along a time series is considered and species loss is more relevant than species replacement. The treatment of both sets of samples will allow us to better distinguish the weight of both components of beta diversity, turnover and nestedness, in the calculation of $N_{90}$.

\section{Results}

\subsection{Non-Real Data}

Results of $N_{90}$ and all the indices of alpha, beta and gamma diversity considered for the non-real data set are presented in Tables 1 and 2. $N_{90}$ showed the highest values $\left(N_{90}=18\right)$ in groups A, B and E, where alpha $H^{\prime}$ and alpha $H_{1}$ also showed the highest value (alpha $H^{\prime}=3$; alpha $\left.H_{1}=20\right)$ and the lowest $\left(N_{90}=9\right)$ in group $\mathrm{D}$, where gamma $S$ was also the lowest (gamma $S=10$ ) from all groups. $N_{90}$ decreased when abundances of $50 \%$ of species decreased to 50\% (group A compared to C), but did not change when all abundances reduced to $50 \%$ (groups A compared to B). $N_{90}$ was lower in F compared to $\mathrm{C}$ and higher compared to D. $N_{90}$ was lower in group $\mathrm{G}$ where nestedness $\left(\beta_{N E S}=0.65\right)$ was higher than in group $\mathrm{H}\left(\beta_{\text {NES }}=0.38\right)$. $N_{90}$ was also lower in group I $\left(\beta_{S O R}=0.74, \beta_{\text {SIM }}\right.$ $=0.61$ and $\left.\beta_{N E S}=0.12\right)$ compared to group J $\left(\beta_{S O R}=0.70, \beta_{S I M}=0.59\right.$ and $\left.\beta_{N E S}=0.10\right)$, where evenness and turnover were lower. $N_{90}$ was higher in J $\left(N_{90}=14.6\right)$ compared to K $\left(N_{90}=14.4\right) . N_{90}$ decreased in group L $\left(N_{90}=13.4\right)$ where the turnover took a low value $\left(\beta_{S I M}=0.32\right)$.

Table 1. Results of $N_{90}$ and alpha, beta and gamma versions of Species Richness $(S)$, Shannon $\left(H^{\prime}\right)$, Hill number of order 1 $\left(H_{1}\right)$ and Pielou's evenness $\left(J^{\prime}\right)$ for the non-real data set. A is the mean abundance in the group of samples.

\begin{tabular}{cccccccccccccccccc}
\hline & \multicolumn{1}{c}{ Alpha } & \multicolumn{4}{c}{ Gamma } & \multicolumn{4}{c}{ Beta } \\
\hline Group & $\mathbf{A}$ & $\boldsymbol{N}_{\mathbf{9 0}}$ & $\boldsymbol{S}$ & $\boldsymbol{H}^{\prime}$ & $\boldsymbol{H}_{\mathbf{1}}$ & $\boldsymbol{J}^{\prime}$ & $\boldsymbol{J}_{\mathbf{1}}$ & $\boldsymbol{S}$ & $\boldsymbol{H}^{\prime}$ & $\boldsymbol{H}_{\mathbf{1}}$ & $\boldsymbol{J}^{\prime}$ & $\boldsymbol{J}_{\mathbf{1}}$ & $\boldsymbol{S}$ & $\boldsymbol{H}^{\prime}$ & $\boldsymbol{H}_{\mathbf{1}}$ & $\boldsymbol{J}^{\prime}$ & $\boldsymbol{J}_{\mathbf{1}}$ \\
\hline A & 200 & 18 & 20 & 3.00 & 20.00 & 1.00 & 1.00 & 20.00 & 3.00 & 20.00 & 1.00 & 1.00 & 1.00 & 1.00 & 1.00 & 1.00 & 1.00 \\
B & 100 & 18 & 20 & 3.00 & 20.00 & 1.00 & 1.00 & 20.00 & 3.00 & 20.00 & 1.00 & 1.00 & 1.00 & 1.00 & 1.00 & 1.00 & 1.00 \\
C & 150 & 17 & 20 & 2.94 & 18.90 & 0.98 & 0.95 & 20.00 & 2.94 & 18.90 & 0.98 & 0.95 & 1.00 & 1.00 & 1.00 & 1.00 & 1.00 \\
D & 100 & 9 & 10 & 2.30 & 10.00 & 1.00 & 1.00 & 10.00 & 2.30 & 10.00 & 1.00 & 1.00 & 1.00 & 1.00 & 1.00 & 1.00 & 1.00 \\
E & 150 & 18 & 20 & 3.00 & 20.00 & 1.00 & 1.00 & 20.00 & 3.00 & 20.00 & 1.00 & 1.00 & 1.00 & 1.00 & 1.00 & 1.00 & 1.00 \\
F & 125 & 13 & 15 & 2.66 & 14.36 & 0.98 & 0.96 & 15.00 & 2.66 & 14.36 & 0.98 & 0.96 & 1.00 & 1.00 & 1.00 & 1.00 & 1.00 \\
G & 110 & 10 & 11 & 2.20 & 11.00 & 1.00 & 1.00 & 20.00 & 2.84 & 17.19 & 0.95 & 0.86 & 1.82 & 1.29 & 1.56 & 0.95 & 0.86 \\
H & 155 & 13.2 & 15.5 & 2.72 & 15.50 & 1.00 & 1.00 & 20.00 & 2.90 & 18.16 & 0.97 & 0.91 & 1.29 & 1.06 & 1.17 & 0.97 & 0.91 \\
I & 100 & 14.4 & 10 & 2.22 & 10.00 & 1.00 & 1.00 & 20.00 & 2.95 & 19.10 & 0.98 & 0.96 & 2.00 & 1.33 & 1.91 & 0.98 & 0.96 \\
J & 112 & 14.6 & 11.2 & 2.38 & 11.20 & 1.00 & 1.00 & 20.00 & 2.95 & 19.01 & 0.98 & 0.95 & 1.79 & 1.24 & 1.70 & 0.98 & 0.95 \\
K & 62.5 & 14.4 & 11.2 & 2.35 & 10.90 & 0.99 & 0.97 & 20.00 & 2.93 & 18.76 & 0.98 & 0.94 & 1.79 & 1.25 & 1.72 & 0.99 & 0.96 \\
L & 127 & 13.4 & 12.7 & 2.44 & 12.70 & 1.00 & 1.00 & 20.00 & 2.94 & 18.88 & 0.98 & 0.94 & 1.57 & 1.20 & 1.49 & 0.98 & 0.95 \\
\hline
\end{tabular}


Table 2. Results of $N_{90}$ and values of $\beta_{S O R}, \beta_{S I M}, \beta_{N E S}$ and within-group similarity (Sim) for the non-real data set. A is the mean abundance in the group of samples.

\begin{tabular}{|c|c|c|c|c|c|c|}
\hline Group & A & $N_{90}$ & $\beta_{\text {SOR }}$ & $\beta_{S I M}$ & $\beta_{N E S}$ & Sim \\
\hline A & 200 & 18 & 0.00 & 0.00 & 0.00 & 100.00 \\
\hline B & 100 & 18 & 0.00 & 0.00 & 0.00 & 100.00 \\
\hline $\mathrm{C}$ & 150 & 17 & 0.00 & 0.00 & 0.00 & 100.00 \\
\hline D & 100 & 9 & 0.00 & 0.00 & 0.00 & 100.00 \\
\hline $\mathrm{E}$ & 150 & 18 & 0.00 & 0.00 & 0.00 & 81.48 \\
\hline $\mathrm{F}$ & 125 & 13 & 0.00 & 0.00 & 0.00 & 100.00 \\
\hline G & 110 & 10 & 0.65 & 0.00 & 0.65 & 63.12 \\
\hline $\mathrm{H}$ & 155 & 13.2 & 0.38 & 0.00 & 0.38 & 88.05 \\
\hline I & 100 & 14.4 & 0.74 & 0.61 & 0.12 & 47.55 \\
\hline $\mathrm{J}$ & 112 & 14.6 & 0.70 & 0.59 & 0.10 & 56.50 \\
\hline $\mathrm{K}$ & 62.5 & 14.4 & 0.70 & 0.59 & 0.10 & 51.81 \\
\hline $\mathrm{L}$ & 127 & 13.4 & 0.64 & 0.32 & 0.31 & 63.38 \\
\hline
\end{tabular}

\subsection{Real Data}

It is seen from the results for all strata and years that the highest correlations with $N_{90}$ are related to the gamma version of $S(\rho=0.735$; Figure 3$)$ and the alpha version of $H_{1}(\rho=0.789$; Figure 3$)$ and $H^{\prime}(\rho=0.667$; Figure 3$) . N_{90}$ also showed a positive correlation with beta $S(\rho=0.544$; Figure 3$)$.
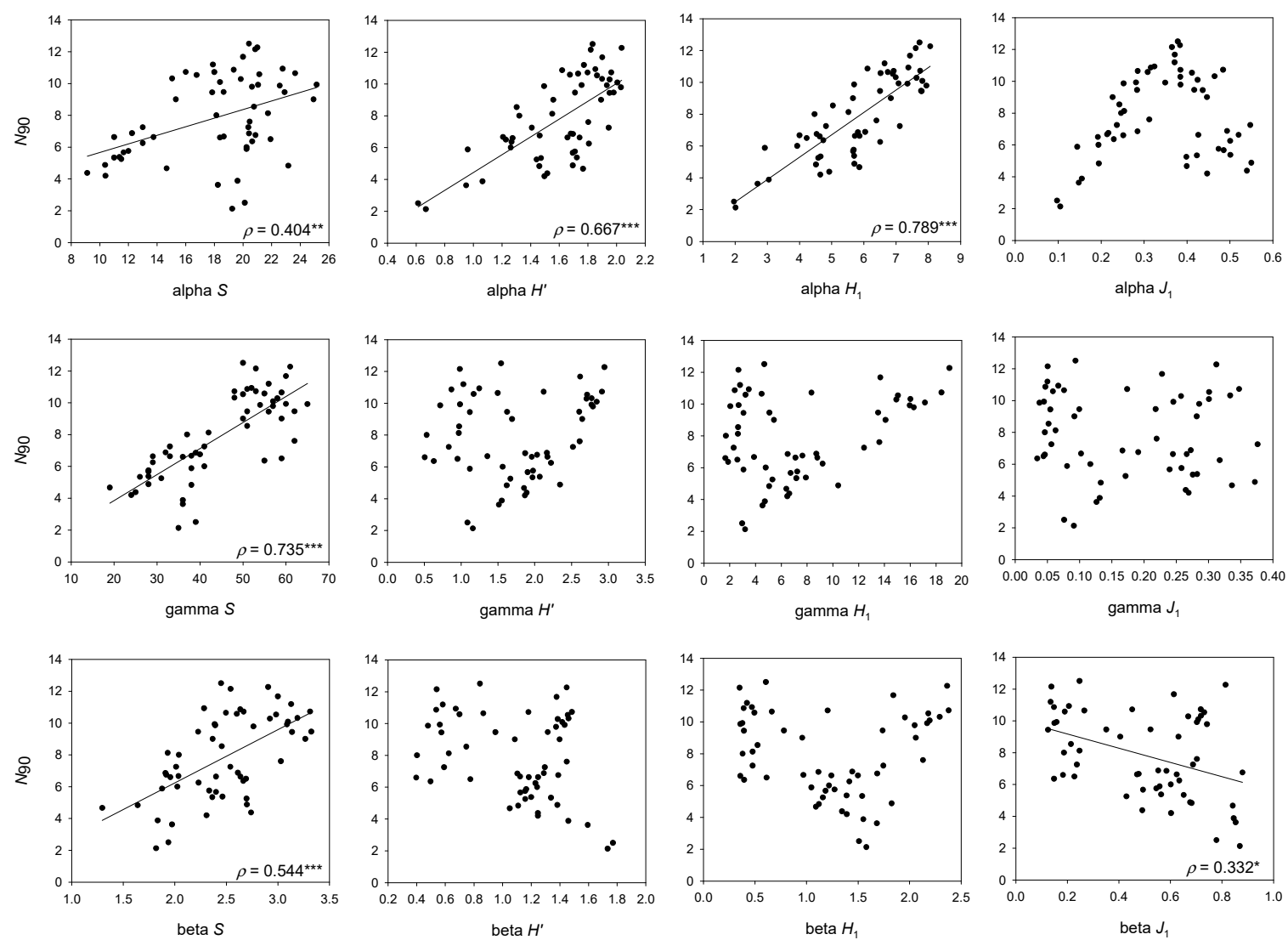

Figure 3. Results of the linear regression analysis of $N_{90}$ with alpha, beta and gamma versions of Species Richness (S), Shannon $\left(H^{\prime}\right)$, Hill number of order $1\left(H_{1}\right)$ and the derived evenness measure $\left(J_{1}\right)$, considering the whole bathymetric range (50-800 $\mathrm{m}$ depth). The results for alpha, beta and gamma versions of $J^{\prime}$ are not plotted because they do not show any correlation with $N_{90}$. Spearman's rank correlation coefficient $(\rho)$, and $p$-values are presented. $\left.\left(^{*}\right) p<0.05 ;{ }^{* *}\right) p<0.01$; $\left.{ }^{* * *}\right) p<0.001$ 
$N_{90}$ showed a positive correlation with $\beta_{\text {SOR }}(\rho=0.718$; Figure 4$)$ and $\beta_{\text {SIM }}(\rho=0.729$; Figure 4), and a negative correlation with $\beta_{N E S}(\rho=-313$; Figure 4$)$ and $\operatorname{Sim}(\rho=-0.576$; Figure 4).

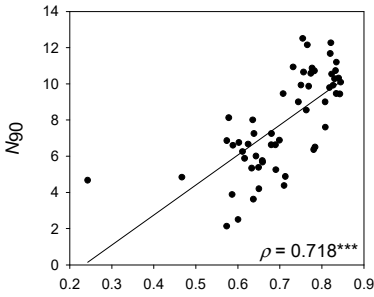

$\beta_{\mathrm{SOR}}$

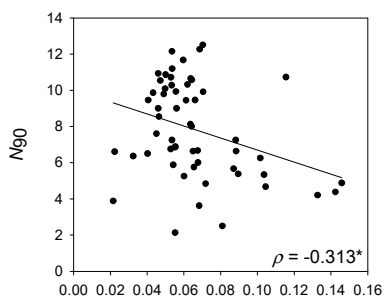

$\beta_{\mathrm{NES}}$

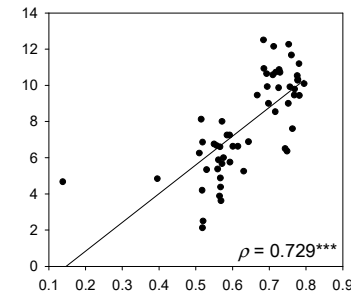

$\beta_{\mathrm{SIM}}$

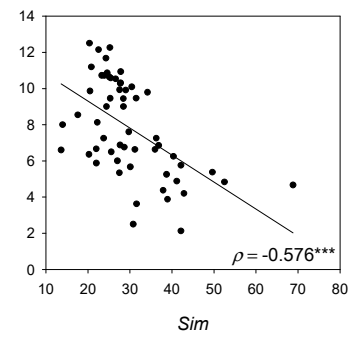

Figure 4. Results of the linear regressions analysis of $N_{90}$ with measures of beta diversity $\beta_{S O R}, \beta_{S I M}$ and $\beta_{N E S}$ and within-group similarity (Sim), considering the whole bathymetric range (50-800 m depth). Spearman's rank correlation coefficient $(\rho)$ and $p$-values are presented. $\quad\left(^{*}\right) p<0.05$; $\left.{ }^{* *}\right) p<0.01 ;(* *) p<0.001$.

The stratum showing the highest values of nestedness was middle slope (501-800 m depth; $\left.\beta_{N E S}=0.095\right)$. For this stratum, $N_{90}$ showed a positive correlation with the gamma version of $S\left(\rho=0.820\right.$; Figure 5), $H^{\prime}(\rho=0.586$; Figure 5$)$ and $H_{1}(\rho=0.586$; Figure 5$)$, and the alpha version of $S(\rho=0.801$; Figure 5$), H_{1}(\rho=0.823$; Figure 5$)$ and $H^{\prime}(\rho=0.605$; Figure 5); and a negative correlation with $\beta_{N E S}(\rho=-0.627$; Figure 6$)$. 

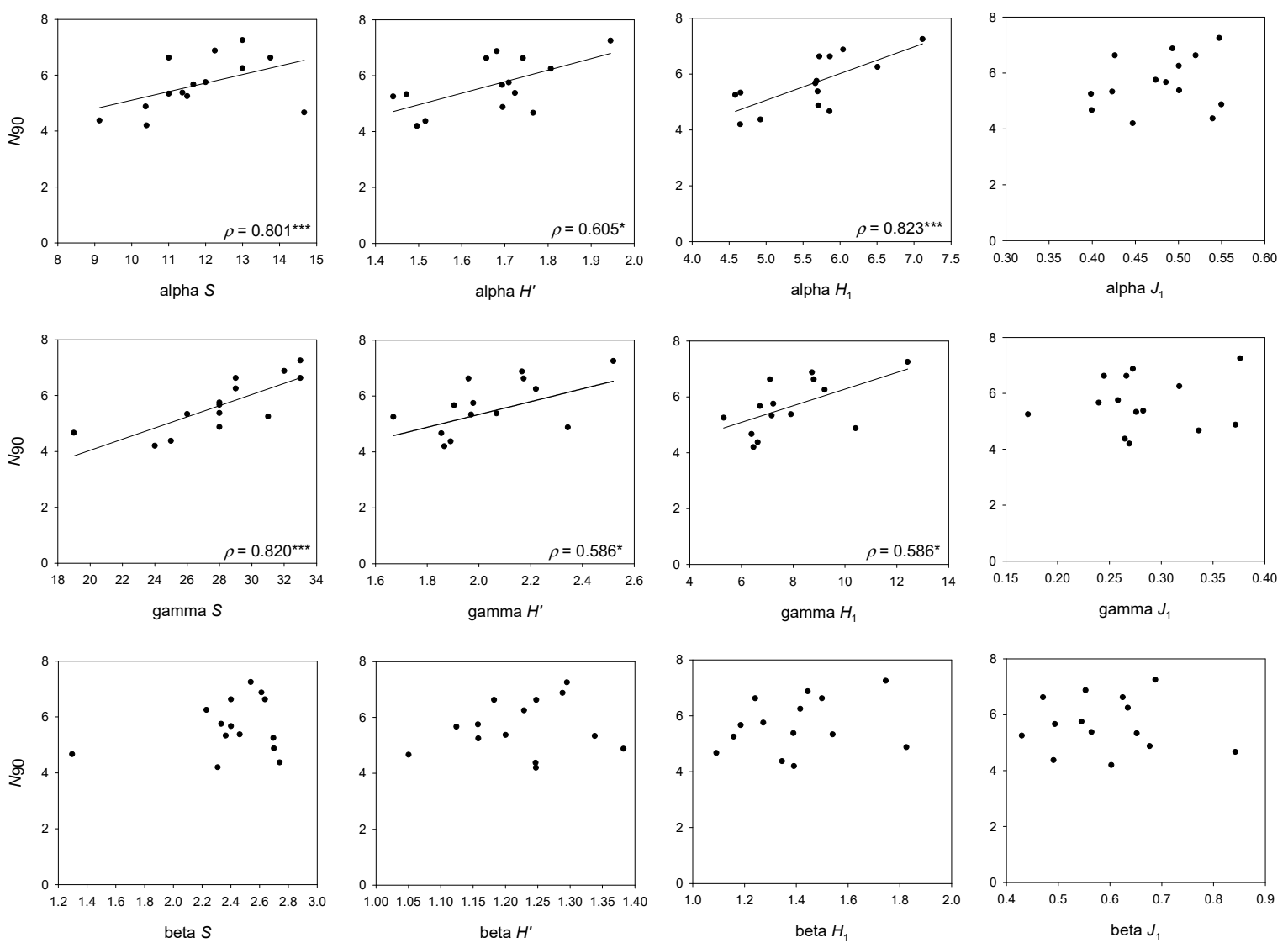

Figure 5. Results of the linear regression analysis of $N_{90}$ with alpha, beta and gamma versions of Species Richness (S), Shannon $\left(H^{\prime}\right)$, Hill number of order $1\left(H_{1}\right)$ and the derived evenness measure $\left(J_{1}\right)$, considering the middle slope stratum (501-800 m depth). The results for alpha, beta and gamma versions of $J^{\prime}$ are not plotted because they do not show any correlation with $N_{90}$. Spearman's rank correlation coefficient $(\rho)$ and $p$-values are presented. $\left({ }^{*}\right) p<0.05 ;\left({ }^{* *}\right) p<0.01$; $(* * *) p<0.001$.
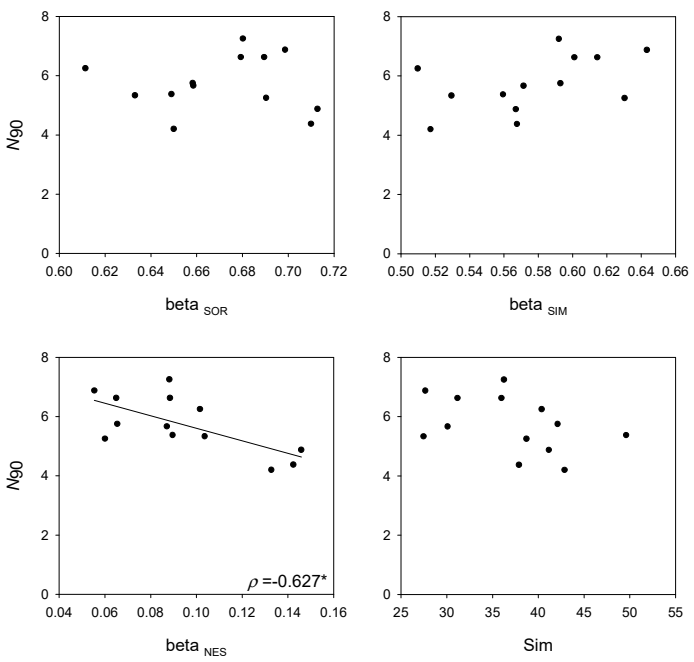

Figure 6. Results of the linear regressions analysis of $N_{90}$ with measures of beta diversity $\beta_{S O R}, \beta_{\text {SIM }}$ and $\beta_{N E S}$ and within-group similarity (Sim) considering the middle slope stratum (501-800 m depth). Spearman's rank correlation coefficient $(\rho)$ and $p$-values are presented. $\left({ }^{*}\right) p<0.05 ;(* *) p<0.01$; $\left.{ }^{* * *}\right) p<0.001$. 


\section{Discussion}

We have presented the $N_{90}$ diversity index, which is based on the results of the SIMPER analysis and represents the number of species contributing up to ninety percent of withingroup similarity in a group of samples. The hypothesis behind the index is that impacted communities may see both the frequency of occurrence and the evenness of the distribution of species abundances reduced among samples. This leads to a decrease in $N_{90}$ due to the retreat of species populations to the localities presenting the most favorable ecological conditions. The $N_{90}$ diversity index has the following advantages when compared to other diversity indices: (i) easy interpretation-units are number of species as in species richness (S), but, at the same time, the high dependence on sample size of $S$ [23-25] is less important in $N_{90}$, as rare species are not usually among the main contributors to within-group similarity; (ii) more sensitivity to anthropogenic impacts and environmental variability and their synergistic effects [13]; (iii) it assesses diversity for the whole set of samples in the group (usually representing a community or ecosystem) instead of operating at sample level and averaging values afterwards, or alternatively, pooling data from different samples (e.g., an $S$ value taking into account all species appearing in all samples); and (iv) species identity is preserved because the $N_{90}$ index is accompanied by a SIMPER table showing within-group species contribution to the $90 \%$ similarity. Finally, thanks to the re-sampling routine implemented in the calculation of $N_{90}$, the index has a dispersion value associated that allows the comparison of values between areas or different periods.

The application of the $N_{90}$ index to a non-real data set has enabled us to see the variation of the index to controlled changes in abundance distribution and number of species between samples in several groups and compare it to a battery of values of other indices. As expected, when abundances of all species are equal, a higher value of $N_{90}$ is reached when these abundances are equally distributed among samples. And like all the other indices, $N_{90}$ do not change when the abundance of all species in all samples changes equally. The main cause of decreases in $N_{90}$ under these limited conditions is the disappearance of species in the group (decreases in gamma $S$ ). In that sense, the null contribution of absent species to Bray-Curtis similarity, and therefore to $N_{90}$, is another advantage of the index, to avoid the consideration of those communities that do not share any species as being similar [15]. $N_{90}$ is also sensitive to abundance evenness at the gamma level, reflected in decreases in the index in groups with identical samples (i.e., maximum similarity) but lower gamma $H^{\prime}, H_{1}$ and $J^{\prime}$. The detection of changes in abundance distribution of species between samples is important in the detection of diversity loss due to the fishing-induced retreatment of species populations to localities presenting the most favourable ecological conditions. For that reason, it is important that $N_{90}$ is based on a measure of similarity between samples influenced by the evenness of abundance at the gamma level, like Bray-Curtis. Besides, the use of absolute abundance in the calculation of $N_{90}$ is preferred to allow the index to capture these changes in abundance distributions. Although these calculations based on non-real data give an idea about the behavior of $N_{90}$ under repeatable and controlled conditions, its application to a real data set allows the analysis of data under natural conditions, with more variations in values of abundance distributions among samples. Changes in $N_{90}$ due to nestedness and turnover of species between samples are discussed below.

For the whole bathymetric range considered, the higher correlation of $N_{90}$ with the effective form of alpha $H^{\prime}$ shows that values of $N_{90}$, whose calculation is based on the comparison of the abundances of each pair of samples composing the group or community, are more similar to a mean value of $H_{1}$ in the samples of the group or the community (alpha $H_{1}$ ) than $H_{1}$ calculated for the whole community (gamma $H_{1}$ ). This means that frequent species in the group or community contribute more to $N_{90}$ than abundant species (i.e., with absolute abundant values) in the whole community. This is endorsed by the high correlation of $N_{90}$ and total number of species in the whole group of samples or community (gamma $S$ ). The difference between alpha, beta and gamma $S$ is that alpha $S$ takes the mean number of species in the community, beta $S$ the replacement of species between samples of 
the community and gamma $S$ is the total number of species in the community. Thus, the high correlation of $N_{90}$ with gamma $S$ has an easy explanation, because the species identity is not lost and the total number of species in the community is taken into account during the calculation of $N_{90}$. However, $N_{90}$ is not equal to gamma $S$, because it only takes into account the species that contribute to $90 \%$ similarity in the group of samples-or in other words, the species that are more representative in terms of frequency of appearance and abundance from the group of samples in the community.

Having $N_{90}$ at halfway between alpha $H_{1}$ and gamma $S$ (mean $N_{90}$ was 7.8, mean gamma $S$ was 44.3 and mean alpha $H_{1}$ was 5.8 , for the whole set of samples) may favor the detection of the reduction in total (gamma) $S$ through reductions in the frequency of occurrence, and on mean (alpha) $H_{1}$ through reductions in the evenness of the distribution of species abundances among samples in impacted communities. Altogether, this would allow the detection of the diversity loss due to fishing.

The positive correlation of $N_{90}$ with beta $S$ denotes that beta $S$ would increase due to an increase in the total number of species (gamma $S$ ), not compensated for by an increase in mean $S$ (alpha $S$ ). However, at least some of the species increasing gamma $S$, although not frequent enough to change the mean $S$, would be evenly distributed enough to contribute to the value of the $N_{90}$, allowing this index to account for some portion of the beta diversity.

$N_{90}$ showed higher correlation with the turnover component of beta diversity than with nestedness, meaning that species replacement between samples has a higher weight in the calculation of the index than species loss. Previous works aimed to detect changes in diversity due to fishing impacts have shown that $N_{90}$ is influenced by both turnover and nestedness. On one hand, species loss was the main cause of decreases in $N_{90}$ in trawled demersal fish communities $[13,26,27]$. On the other, changes in diversity of epibenthic communities due to trawling were detected through the replacement of some vulnerable species by others more adapted to fishing, hence not involving a decrease in $N_{90}$ values between impacted and non-impacted areas [28]; in that sense, we could expect that nestedness would be more important component of $N_{90}$ than turnover. However, considering the data analyzed includes a large bathymetric range (50-800 $\mathrm{m}$ depth), turnover seems more plausible than species loss because the main factor structuring the community in the study area, as in the rest of the Mediterranean (e.g., [27]), is depth and not fishing impact. In any case, and because both processes can influence the results of $N_{90}$, it is important to emphasize that the identity of the species is not lost during its calculation and the associated SIMPER table with the species contribution to similarity permits the knowledge of which species contribute to $N_{90}$ and if changes in $N_{90}$ are due to loss or replacement of species in the community.

Within-group similarity can be seen as an inverse measure of beta diversity and is based on the Bray-Curtis similarity index, which includes abundance of species in the calculation. On the contrary, measures of turnover and nestedness are calculated from presence-absence data [7]. The lower correlation of $N_{90}$ and within-group similarity compared to measures of nestedness and turnover reinforces the idea conceived from this work that the frequency of appearances of species has more weight in the calculation of $N_{90}$ than the distribution of abundances between samples. However, the high correlation of $N_{90}$ with beta diversity measures and the fact that it is an indexed measure whose calculation relies on a similarity index, lead to it being included in the group of beta diversity indices.

The application of the analysis to middle slope stratum deepens in the results obtained for the whole depth range. In this stratum the correlation of $N_{90}$ with alpha and gamma $S$ increases. Additionally, $N_{90}$ shows a higher correlation with nestedness than with turnover components of beta diversity. The difference between the whole depth range analysis and middle slope is that in the last case, the same community is considered in different years, whereas several demersal fish communities are considered when we analyze the larger depth gradient (e.g., [26,27]). Altogether, this indicates that $N_{90}$ reflects an increase in gamma $S$ due to the replacement of species between different communities when the whole depth range is considered, reflected by an increase of $N_{90}$. While in a particular stratum, 
i.e., within the same bathymetric assemblage where species turnover or replacement is lower between samples, species loss and differences in number of species are the main causes of change. However, and contrary to communities mainly influenced by turnover, the fact that nestedness can impact gamma $H_{1}$, which in turn impacts $N_{90}$, must also be considered. In any case, $N_{90}$ provides different information depending on whether we analyze heterogeneous or homogenous communities, with communities in which more species show a more even spread of their abundance showing higher values of $N_{90}$ at any gradient of change.

Again, the associated SIMPER results will allow us to elucidate the relative importance of nestedness and turnover components of beta diversity on $N_{90}$, and hence, identify the effects of impacts on marine communities. This has been proved in previous works where SIMPER tables allowed the identification of species that disappeared from the community due to their vulnerability to fishing activities, like elasmobranchs, or to their state of exploitation, like some by-catch species of bottom trawl fishery in the Balearic Islands in areas subjected to a high level of bottom trawling [13]. It also allowed the identification of species replaced by smaller ones in a trawled area [28]. As such, the study of the ecology of species that contribute to $N_{90}$ through the SIMPER table is relevant to determine if fishing has caused a change in diversity due to the loss of vulnerable species or replacement by those more adapted to fishing impacts. However, this advantage is also useful for general ecological studies, in order to detect which kind of species are structuring the community.

Up to now, the $N_{90}$ index has contributed to the comparison and explanation of specific data pools of exploited marine ecosystems and their living resources; it has been applied in the Mediterranean to assess the impact of fishing exploitation on the diversity of demersal fish and epi-benthic communities, both at narrow and broad bathymetric and geographical scales and considering both continuous and stratified approaches regarding levels of fishing effort [13,26-28]. In all cases, $N_{90}$ displayed a better response to fishing pressure compared to other diversity indices covering a wide variety of aspects like the number of species and their relative abundance, as well as their taxonomic and functional position [23,29-33] Table 3, showing lower values in impacted communities. $N_{90}$ has also been applied to assess spatio-temporal variations of diversity in fishing waste from northwestern Mediterranean bottom trawl fishery [34]. In that case, similar results were obtained for species richness, but $N_{90}$ gave information not only about the number of species but also on the species composition of the waste.

Table 3. Diversity indices which have been compared to the $N_{90}$ in previous studies [23,29-33].

\begin{tabular}{|c|c|c|}
\hline Index & Description & Reference \\
\hline Species richness & Total number of species & \\
\hline Shannon & $\begin{array}{c}\text { Measure of uncertainty about the species of the nearest neighbour of an } \\
\text { individual from the community }\end{array}$ & [29] \\
\hline Margalef's richness & Number of species adjusted to the number of individuals & [30] \\
\hline Pielou's evenness & Equitability in the distribution of abundances of species in a community & [31] \\
\hline Reciprocal Berger-Parker & Inverse of the dominance of species & [23] \\
\hline Taxonomic distinctness & $\begin{array}{c}\text { Taxonomic distance expected between two individuals randomly selected, } \\
\text { considering that they belong to different species }\end{array}$ & [32] \\
\hline Functional diversity & Functional distance expected between two individuals randomly selected & [33] \\
\hline Functional distinctness & $\begin{array}{l}\text { Functional distance expected between two individuals randomly selected, } \\
\text { considering that they belong to different species }\end{array}$ & [33] \\
\hline
\end{tabular}

Indicators, defined as variables, pointers or indices of a phenomenon, are needed to support the implementation of the Ecosystem Approach to Fisheries, as they can provide information on the state of the ecosystems by tracking those components and attributes that may be adversely impacted by fishing, like diversity [35]. For the above-mentioned reasons, the $N_{90}$ index can be a useful indicator for this. In addition, $N_{90}$ also detects fishing impacts by fluctuating in response to environmental variation [11], making this index sensitive to 
the synergies between climate and fishing impacts at the community level. The sensitivity of $N_{90}$ to reductions in the frequency of occurrence and the evenness of the distribution of species abundances among samples in impacted communities, together with the identification of both effects of fishing impacts, species replacement and species loss [13,26,28], make the $N_{90}$ diversity index an alternative to 'traditional' diversity indices when trying to monitor fishing impacts within the current context of global change. Additionally, the comparison of $N_{90}$ with a battery of indices to explore its properties performed here will make it more useful to those who decide to use it.

Supplementary Materials: The following are available online at https:/ / www.mdpi.com/article/10 .3390/d13100489/s1, Non-real data set: 'nonreal_sp.csv' and 'nonreal_group.csv', R script to calculate $N_{90}$ : N90_script.R, Appendix A data set: Data_sp.csv and Data_group.csv.

Author Contributions: Conceptualization, M.T.F., F.O. and E.M.; Funding acquisition, E.M.; Methodology, M.T.F. and F.O.; Software, M.T.F.; Supervision, F.O. and E.M.; Writing-original draft, M.T.F.; Writing - review \& editing, F.O. and E.M. All authors have read and agreed to the published version of the manuscript.

Funding: The MEDITS scientific surveys are funded by the European Union Data Collection Framework for the Common Fisheries Policy. M. Teresa Farriols was supported by a FPI Fellowship (BES2013-065112), which was developed within ECLIPSAME (CTM2012-37701) and CLIFISH (CTM201566400-C3-1-R MINECO/FEDER). Both fellowship and projects were funded by the Spanish Ministry of Economy and Competitiveness. More recently this research has been funded and performed within the scope of the LIFE IP INTEMARES project, coordinated by the Biodiversity Foundation of the Ministry for the Ecological Transition and the Demographic Challenge and receiving the financial support from the European Union's LIFE programme (LIFE15 IPE ES 012).

Institutional Review Board Statement: Ethical review and approval were waived for this study, due that real data have been obtained in the framework of the MEDITS research surveys, which follow a sampling scheme and standartized protocol approved by international authorities (EU/DG Mare, FAO/GFCM). If a live specimen of a rare species or a species subject to conservation measures was caught, it was quickly sampled (4-5 minutes) and returned back to the sea unharmed, giving it a chance for survival, following the recommendation GFCM/36/2012/3 (http:/ /www.gfcmonline.org/ decisions /) on fisheries management measures for conservation of sharks and rays in the GFCM area.

Data Availability Statement: No new data were created or analyzed in this study. Data sharing is not applicable to this article. In any case, the access to the MEDITS data base was formerly regulated by the EU Reg. 199/2008 (Data Collection Framework) and currently by the regulation (EU) 2017/1004 (recast).

Acknowledgments: The present study could not have been done without the work of all the participants and crew during the MEDITS scientific surveys. The authors thank Eduard Szöcs and Paz Sampedro very much for their help and guidance in developing the script, as well as the valuable comments of two anonymous referees that helped us to improve the manuscript.

Conflicts of Interest: The authors declare no conflict of interest.

\section{Appendix A. N90 Script}

Appendix A.1. Data Sets

$N_{90}$ was calculated using an R script, version 4.4.1 [16]. The data needed to work with the N90 script consists of two '.csv' files. The first one includes the abundances of each species. In this data file, column labels are the species names and each row corresponds to a sample. The other file includes, in the same order as the previous one, a column named Group, indicating the group to which each sample belongs. These data sets must be imported with the names $a f$ (i.e., abundance file) and $g f$ (i.e., groups file). The structure of $a f$ and $g f$ is shown in Table A1. The Vegan package [17] is required to carry out all the analyses.

As an example, we have applied the N90 script functions to a non-real data set ('Data_group.csv' and 'Data_sp.csv' files). Table A1 shows the abundances of 13 species (A, 
B, C, D, E, F, G, H, I, J, K, L, and M) in 2 unique groups of samples named gA and gB. The data must be imported with the names af and $g f$ from 2 '.csv' files.

Table A1. Abundance data by species and sample for each Group of samples used in the example. The columns under af show the data included in the abundance file, whereas the column under $g f$ shows the data included in the groups file. A, B, C, D, E, F, G, H, I, J, K, L and M are the names of the species.

\begin{tabular}{|c|c|c|c|c|c|c|c|c|c|c|c|c|c|}
\hline & & & & & & af & & & & & & & gf \\
\hline A & B & C & D & $\mathrm{E}$ & $\mathbf{F}$ & G & $\mathbf{H}$ & I & $\mathbf{J}$ & $\mathbf{K}$ & L & $\mathbf{M}$ & Group \\
\hline 0 & 0 & 0 & 23 & 23 & 0 & 0 & 0 & 0 & 0 & 0 & 235 & 0 & gA \\
\hline 0 & 0 & 0 & 0 & 0 & 0 & 0 & 0 & 0 & 148 & 0 & 49 & 0 & gA \\
\hline 0 & 0 & 0 & 47 & 0 & 24 & 0 & 0 & 284 & 0 & 24 & 0 & 0 & gA \\
\hline 0 & 0 & 0 & 22 & 0 & 0 & 22 & 0 & 66 & 0 & 66 & 22 & 0 & gA \\
\hline 0 & 0 & 0 & 0 & 0 & 0 & 0 & 0 & 578 & 0 & 46 & 0 & 0 & gA \\
\hline 415 & 0 & 0 & 0 & 0 & 0 & 0 & 0 & 394 & 0 & 0 & 109 & 0 & gA \\
\hline 0 & 0 & 175 & 0 & 0 & 0 & 0 & 0 & 0 & 197 & 197 & 372 & 0 & gA \\
\hline 0 & 0 & 0 & 215 & 0 & 0 & 0 & 0 & 882 & 0 & 473 & 0 & 1269 & gA \\
\hline 41 & 0 & 20 & 41 & 0 & 0 & 20 & 0 & 569 & 203 & 996 & 41 & 0 & gA \\
\hline 39 & 0 & 20 & 20 & 0 & 0 & 0 & 0 & 255 & 0 & 39 & 79 & 1336 & gA \\
\hline 43 & 0 & 43 & 299 & 0 & 0 & 0 & 0 & 2542 & 0 & 2392 & 0 & 0 & $\mathrm{gB}$ \\
\hline 22 & 0 & 0 & 90 & 0 & 112 & 0 & 0 & 4969 & 0 & 627 & 0 & 67 & $\mathrm{gB}$ \\
\hline 0 & 0 & 0 & 172 & 0 & 0 & 0 & 0 & 6919 & 0 & 57 & 0 & 96 & $\mathrm{gB}$ \\
\hline 0 & 0 & 0 & 169 & 0 & 0 & 19 & 0 & 226 & 0 & 414 & 19 & 0 & $\mathrm{gB}$ \\
\hline 0 & 21 & 21 & 63 & 126 & 0 & 0 & 0 & 0 & 0 & 820 & 147 & 84 & $\mathrm{gB}$ \\
\hline 19 & 0 & 0 & 58 & 0 & 0 & 0 & 0 & 1451 & 0 & 0 & 19 & 0 & $\mathrm{gB}$ \\
\hline 0 & 0 & 81 & 0 & 0 & 0 & 61 & 0 & 0 & 606 & 20 & 323 & 0 & $\mathrm{gB}$ \\
\hline 0 & 0 & 0 & 74 & 0 & 18 & 0 & 0 & 129 & 18 & 147 & 0 & 0 & $\mathrm{gB}$ \\
\hline 38 & 0 & 19 & 208 & 0 & 0 & 0 & 0 & 5179 & 0 & 151 & 0 & 1115 & $\mathrm{gB}$ \\
\hline 72 & 0 & 0 & 192 & 0 & 0 & 0 & 48 & 3006 & 0 & 577 & 0 & 24 & $\mathrm{gB}$ \\
\hline 56 & 0 & 37 & 111 & 0 & 0 & 0 & 37 & 130 & 19 & 167 & 93 & 501 & $\mathrm{gB}$ \\
\hline 0 & 0 & 37 & 130 & 0 & 0 & 0 & 0 & 5329 & 0 & 3182 & 0 & 0 & $\mathrm{gB}$ \\
\hline 18 & 0 & 165 & 202 & 0 & 0 & 0 & 0 & 3813 & 0 & 1540 & 0 & 1228 & $\mathrm{gB}$ \\
\hline 55 & 0 & 92 & 18 & 0 & 0 & 18 & 0 & 4055 & 110 & 1468 & 0 & 18 & $\mathrm{gB}$ \\
\hline 0 & 0 & 538 & 0 & 0 & 0 & 36 & 0 & 18 & 341 & 72 & 269 & 18 & $\mathrm{gB}$ \\
\hline 0 & 0 & 805 & 98 & 39 & 0 & 0 & 0 & 20 & 393 & 1374 & 569 & 2061 & $\mathrm{gB}$ \\
\hline 273 & 0 & 243 & 273 & 0 & 0 & 30 & 0 & 1031 & 0 & 576 & 121 & 909 & $\mathrm{gB}$ \\
\hline 60 & 0 & 0 & 80 & 0 & 0 & 20 & 40 & 40 & 60 & 498 & 179 & 0 & $\mathrm{gB}$ \\
\hline 19 & 0 & 0 & 93 & 0 & 0 & 0 & 75 & 1325 & 0 & 523 & 0 & 0 & $\mathrm{gB}$ \\
\hline 19 & 0 & 0 & 19 & 0 & 0 & 0 & 0 & 8519 & 0 & 167 & 0 & 1318 & $\mathrm{gB}$ \\
\hline 18 & 0 & 0 & 0 & 0 & 0 & 18 & 0 & 733 & 0 & 72 & 0 & 0 & $\mathrm{gB}$ \\
\hline 0 & 0 & 0 & 0 & 0 & 0 & 0 & 0 & 0 & 425 & 0 & 58 & 0 & $\mathrm{gB}$ \\
\hline 0 & 0 & 0 & 0 & 38 & 0 & 19 & 0 & 0 & 0 & 303 & 114 & 132 & $\mathrm{gB}$ \\
\hline 0 & 0 & 0 & 37 & 0 & 0 & 0 & 18 & 3118 & 0 & 1339 & 0 & 18 & $\mathrm{gB}$ \\
\hline 0 & 0 & 0 & 59 & 0 & 0 & 0 & 59 & 2121 & 0 & 238 & 0 & 1407 & $\mathrm{gB}$ \\
\hline 21 & 0 & 0 & 21 & 0 & 0 & 0 & 0 & 2987 & 0 & 165 & 0 & 0 & $\mathrm{gB}$ \\
\hline 0 & 0 & 370 & 0 & 0 & 0 & 0 & 0 & 0 & 206 & 62 & 637 & 0 & $\mathrm{gB}$ \\
\hline 0 & 0 & 40 & 20 & 20 & 0 & 0 & 0 & 0 & 0 & 418 & 358 & 219 & $\mathrm{gB}$ \\
\hline 0 & 0 & 20 & 40 & 0 & 0 & 0 & 81 & 161 & 20 & 1732 & 624 & 20 & $\mathrm{gB}$ \\
\hline 24 & 0 & 235 & 400 & 0 & 0 & 0 & 71 & 3695 & 0 & 1695 & 47 & 4590 & $\mathrm{gB}$ \\
\hline
\end{tabular}

\section{Appendix A.2. Exploring Data}

The Data_explore ( $a f, g f$, perc, perc2) function allows the exploration of the data prior to application of the jack-knife re-sampling routine. For each Group given in $g f$ it returns: (1) the number of samples in each group (n); (2) the number of samples that will be removed in each re-sampling ( $n 1)$ for a specified percentage of samples to be removed (perc; if perc accounts for less than one sample, the function will consider $n 1=1$ by default); and (3) the maximum number of samples in $n 1$ that can be repeated in the next re-sampling for a specified percentage perc2. Both perc and perc 2 are implemented as integer divisions in the 
script. This function allows users to explore the samples replaced in each jack-knife using different values of perc and perc2.

We applied the Data_explore ( $a f$, $g f$, perc $=10$, perc $2=70$ ) function, in which 10 percent of samples were removed in each re-sampling (perc), and 70 percent of removed samples were repeated from the previous resampling (perc2) to the non-real data set in Section 1.

For our example data set the output was:

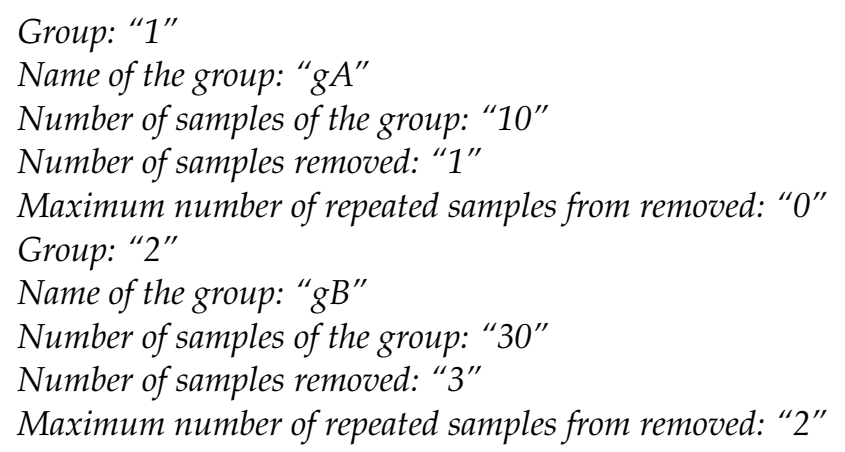

This shows that in the first group (gA) there are 10 samples and that the number of samples removed in each re-sampling with the given percentage (perc $=10$ ) is $n 1=1$, of which none should be repeated according to the given perc2 $($ perc $2=70)$. In the second group $(\mathrm{gB})$ there are 30 samples; the number of samples removed in each re-sampling with the given percentage (perc $=10)$ is $n 1=3$. The number of samples that should can be repeated according perc2 $($ perc $2=70)$ is 2 .

\section{Appendix A.3. Resampling N90}

The N90_resampling ( $a f, g f$, cutoff $=90$, perc, perc2, jkmax) function executes the jack-knife re-sampling routine and returns the value of the $N_{90}$ index. With the value of $j k m a x$, the user can specify the number of re-samples to be done. The maximum value of $j k m a x$ permitted for the script is 9999. If this value is overtaken, the function will return a 'WARNING' message. The argument cutoff allows specification of a different cutoff percentage of accumulated species contribution to within-group similarity than the $90 \%$ used by default in the $N_{90}$ index (i.e., cutoff $=\mathrm{y}$ then $N_{\mathrm{y}}$ ). The use of the arguments perc and perc 2 has been already explained for the Data_explore (af, gf, perc, perc2) function in Section 2.

At the end of the calculation, the N90_resampling (af, gf, cutoff $=90$, perc, perc2, jkmax) function returns a list with 3 objects. The \$N90_jackknifes object reports the value of the $n_{90}$ index (n90.jackknife) and the within-group similarity (Sim.jackknife) obtained in each re-sampling for each Group given in $g f$. The $\$ N 90 \_$mean_values object reports the mean value of the $N_{90}$ index (Av.N90) and its standard deviation (SD.N90), and the mean within-group similarity (Av.Sim) and its standard deviation (SD.Sim), both calculated taking into account all the values obtained in each re-sampling for each Group given in $g f$. And finally, the \$SIMPER_table object includes a SIMPER table for each Group given in $g f$ that shows the contribution of all the species included in the group of samples. These SIMPER tables are generated taking into account all the samples (i.e., without re-sampling). For each Species in a Group the table shows: the mean abundance (Av.Abund) and its standard deviation (SD.Abund), the mean contribution (Av.Si) and its standard deviation (SD.Si) to within-group similarity, the percentage contribution to within-group similarity (Contr), and the cumulative contribution to within-group similarity (Cum).

For the present example, N90_resampling (af, $g f, \operatorname{cutoff}=90, \operatorname{perc}=10, \operatorname{perc} 2=70$, $j k$ max $=9999$ ), the perc $=10$ and the perc $2=70$ previously explored in Section 2, are used. The output list (named as my_list in N90 script) consists of 3 objects: The \$N90_jackknifes object summarizing the results of the $n_{90}$ value and the mean within-group similarity in each re-sampling (Table A2); the $\$ N 90 \_$mean_values object summarizing the $N_{90}$ value and the mean within-group similarity, with their standard deviations for all groups in $g f$ (Table A3); finally, the \$SIMPER_table object summarizing the SIMPER analysis results 
for each group of samples (Table A4). This table will allow identification of the species accounting for the $N_{90}$ value due to their being ordered by their contribution to withingroup similarity.

Table A2. Jack-knife results table obtained using the N90_resampling function for group A (gA) from the $\$ N 90 \_j a c k k n i f e s$ object. n90_jackknife and Sim_jackknife are the values of the $n_{90}$ and the total similarity values in each re-sampling step, respectively.

\begin{tabular}{ccc}
\hline Group & n90_jackknife & Sim_jackknife \\
\hline gA & 5 & 23.727 \\
gA & 4 & 24.326 \\
gA & 5 & 20.527 \\
gA & 5 & 22.314 \\
gA & 5 & 19.980 \\
gA & 5 & 20.616 \\
gA & 4 & 22.541 \\
gA & 4 & 21.070 \\
gA & 4 & 20.011 \\
gA & 4 & 21.217 \\
\hline
\end{tabular}

Table A3. Average results table obtained using the N90_resampling function from the $\$ N 90 \_m e a n$ values object. Av.N90 and the SD.N90 are the $N_{90}$ value and its standard deviation, respectively; Av.Sim and SD.Sim are the average and standard deviation values of the within-group similarity.

\begin{tabular}{ccccc}
\hline Group & Av.N90 & SD.N90 & Av.Sim & SD.Sim \\
\hline gA & 4.5 & 0.527 & 21.633 & 1.529 \\
gB & 4.395 & 0.490 & 29.631 & 1.201 \\
\hline
\end{tabular}

Table A4. SIMPER table obtained using the N90_resampling function from the \$SIMPER_table object. Av.Abund and SD.Abund are the average and standard deviation values of the abundance, respectively; Av.Si and SD.Si are the mean and standard deviation of the contribution of each species to the within-group similarity; Contr is the percentage contribution to within-group similarity; and Cum is the cumulative percentage contribution.

\begin{tabular}{cccccccc}
\hline Group & Species & Av.Abund & SD.Abund & Av.Si & SD.Si & Contr & Cum \\
\hline gA & I & 302.8 & 302.612 & 11.120 & 15.557 & 51.403 & 51.403 \\
gA & L & 90.7 & 122.035 & 3.964 & 7.167 & 18.325 & 69.727 \\
gA & K & 184.1 & 320.450 & 2.795 & 4.442 & 12.919 & 82.646 \\
gA & M & 260.5 & 549.409 & 1.219 & 8.177 & 5.635 & 88.281 \\
gA & J & 54.8 & 89.375 & 1.192 & 4.754 & 5.510 & 93.791 \\
gA & D & 36.8 & 64.966 & 1.039 & 2.092 & 4.805 & 98.596 \\
gA & A & 49.5 & 129.497 & 0.175 & 0.668 & 0.807 & 99.403 \\
gA & C & 21.5 & 54.572 & 0.087 & 0.334 & 0.404 & 99.807 \\
gA & G & 4.2 & 8.867 & 0.042 & 0.280 & 0.193 & 100 \\
gB & I & 2050.533 & 2371.281 & 14.989 & 21.685 & 50.584 & 50.584 \\
gB & K & 693.2 & 796.607 & 8.342 & 9.584 & 28.153 & 78.737 \\
gB & L & 119.233 & 194.182 & 1.769 & 4.734 & 5.970 & 84.708 \\
gB & M & 460.833 & 957.334 & 1.665 & 4.667 & 5.618 & 90.326 \\
gB & D & 97.533 & 101.775 & 1.265 & 1.801 & 4.269 & 94.594 \\
gB & J & 73.267 & 157.214 & 0.687 & 3.979 & 2.318 & 96.912 \\
gB & C & 91.533 & 184.478 & 0.522 & 1.992 & 1.763 & 98.675 \\
gB & A & 25.233 & 51.494 & 0.182 & 0.470 & 0.613 & 99.288 \\
gB & G & 7.367 & 14.454 & 0.096 & 0.414 & 0.323 & 99.611 \\
gB & H & 14.3 & 26.373 & 0.088 & 0.398 & 0.298 & 99.909 \\
gB & E & 7.433 & 24.624 & 0.026 & 0.253 & 0.087 & 99.996 \\
gB & F & 4.333 & 20.599 & 0.001 & 0.028 & 0.004 & 100 \\
\hline
\end{tabular}




\section{References}

1. Magurran, A.E. Measuring Biological Diversity; Blackwell Science Ltd.: Oxford, UK, 2004.

2. Chao, A.; Chiu, C.H.; Hsieh, T.C. Proposing a resolution to debates on diversity partitioning. Ecology 2012, 93, $2037-2051$. [CrossRef] [PubMed]

3. Chao, A.; Gotelli, N.J.; Hsieh, T.C.; Sander, E.L.; Ma, K.H.; Colwell, R.K.; Ellison, A.M. Rarefaction and extrapolation with Hill numbers: A framework for sampling and estimation in species diversity studies. Ecol. Monogr. 2014, 84, 45-67. [CrossRef]

4. Jost, L. Partitioning diversity into independent alpha and beta components. Ecology 2007, 88, 2427-2439. [CrossRef] [PubMed]

5. Jurasinski, G.; Retzer, V.; Beierkuhnlein, C. Inventory, differentiation, and proportional diversity: A consistent terminology for quantifying species diversity. Oecologia 2009, 159, 15-26. [CrossRef] [PubMed]

6. Tuomisto, H. A consistent terminology for quantifying species diversity? Yes, it does exist. Oecologia 2010, 164, 853-860. [CrossRef]

7. Baselga, A. Partitioning the turnover and nestedness components of beta diversity. Glob. Ecol. Biogeogr. 2010, 19, 134-143. [CrossRef]

8. Whittaker, R.H. Vegetation of the Siskiyou mountains, Oregon and California. Ecol. Monogr. 1960, 30, 279-338. [CrossRef]

9. Whittaker, R.H. Evolution and measurement of species diversity. Taxon 1972, 12, 213-251. [CrossRef]

10. Chao, A.; Chiu, C.H. Bridging the variance and diversity decomposition approaches to beta diversity via similarity and differentiation measures. Methods Ecol. Evol. 2016, 7, 919-928. [CrossRef]

11. Legendre, P.; Borcard, D.; Peres-Neto, P.R. Analysing beta diversity: Partitioning the spatial variation and community composition data. Ecol. Monogr. 2005, 75, 435-450. [CrossRef]

12. Anderson, M.J.; Ellingsen, K.E.; McArdle, B.H. Multivariate dispersion as a measure of beta diversity. Ecol. Lett. 2006, 9, 683-693. [CrossRef]

13. Farriols, M.T.; Ordines, F.; Hidalgo, M.; Guijarro, B.; Massutí, E. N90 index: A new approach to biodiversity based on similarity and sensitive to direct and indirect fishing impact. Ecol. Indic. 2015, 52, 245-255. [CrossRef]

14. Clarke, K.R. Non-parametric multivariate analyses of changes in community structure. Aust. J. Ecol. 1993, 18, 117-143. [CrossRef]

15. Bray, J.R.; Curtis, J.T. An ordination of the upland forest communities of southern Wisconsin. Ecol. Monogr. 1957, 27, 325-349. [CrossRef]

16. R Core Team. R: A Language and Environment for Statistical Computing. Available online: http://www.r-project.org/ (accessed on 20 September 2021).

17. Oksanen, J.; Blanchet, F.G.; Kindt, R.; Legendre, P.; Minchin, P.R.; O’Hara, R.B.; Simpson, G.L.; Solymos, P.; Stevens, M.H.H.; Wagner, H. Vegan: Community Ecology Package. Available online: https:/ CRAN.R-project.org/package=vegan (accessed on 20 September 2021).

18. Sørensen, T.A. A method of establishing groups of equal amplitude in plant sociology based on similarity of species content, and its application to analyses of the vegetation on Danish commons. K. Dan. Vidensk. Selsk. Biol. Skr. 1948, 5, 1-34.

19. Koleff, P.; Gaston, K.J.; Lennon, J.K. Measuring beta diversity for presence-absence data. J. Anim. Ecol. 2003, 72, 367-382. [CrossRef]

20. Simpson, G.G. Mammals and the nature of continents. Am. J. Sci. 1943, 241, 1-31. [CrossRef]

21. Lennon, J.J.; Koleff, P.; Greenwood, J.J.D.; Gaston, K.J. The geographical structure of British bird distributions: Diversity, spatial turnover and scale. J. Anim. Ecol. 2001, 70, 966-979. [CrossRef]

22. Spedicato, M.T.; Massutí, E.; Mérigot, B.; Tserpes, G.; Jadaud, A.; Relini, G. The MEDITS trawl survey specifications in an ecosystem approach to fishery management. Sci. Mar. 2019, 83, 9-20. [CrossRef]

23. Hill, M.O. Diversity and evenness: A unifying notation and its consequences. Ecology 1973, 54, 427-432. [CrossRef]

24. Noss, R.F. Indicators for monitoring biodiversity: A hierarchical approach. Conserv. Biol. 1990, 4, 355-364. [CrossRef]

25. Gotelli, N.J.; Chao, A. Measuring and estimating species richness, species diversity, and biotic similarity from sampling data. In Encyclopedia of Biodiversity; Levin, S.A., Ed.; Academic Press: Waltham, MA, USA, 2013; pp. 195-211.

26. Farriols, M.T.; Ordines, F.; Somerfield, P.J.; Pasqual, C.; Hidalgo, M.; Guijarro, B.; Massutí, E. Bottom trawl impacts on Mediterranean demersal fish diversity: Not so obvious or are we too late? Cont. Shelf Res. 2017, 137, 84-102. [CrossRef]

27. Farriols, M.T.; Ordines, F.; Carbonara, P.; Casciaro, L.; Di Lorenzo, M.; Esteban, A.; Follesa, C.; García-Ruiz, C.; Isajlovic, I.; Jadaud, A.; et al. Spatio-temporal trends in diversity of demersal fish assemblages in the mediterranean. Sci. Mar. 2019, 83, 189-206. [CrossRef]

28. Ordines, F.; Ramón, M.; Rivera, J.; Rodríguez-Prieto, C.; Farriols, M.T.; Guijarro, B.; Pasqual, C.; Massutí, E. Why long term trawled red algae beds off Balearic Islands (western Mediterranean) still persist? Reg. Stud. Mar. Sci. 2017, 15, 39-49. [CrossRef]

29. Shannon, C.E.; Weaver, W. The Mathematical Theory of Communication; University of Illinois Press: Urbana, IL, USA, 1949.

30. Margalef, R. Information theory in ecology. Gen. Syst. 1958, 3, 36-71.

31. Pielou, E.C. Species-diversity and pattern-diversity in the study of ecological succession. J. Theor. Biol. 1966, 10, 370-383. [CrossRef]

32. Warwick, R.M.; Clarke, K.R. New 'biodiversity' measures reveal a decrease in taxonomic distinctness with increasing stress. Mar Ecol. Prog. Ser. 1995, 129, 301-305. [CrossRef]

33. Somerfield, P.J.; Clarke, K.R.; Warwick, R.M.; Dulvy, N.K. Average functional distinctness as a measure of the composition of assemblages. ICES J. Mar. Sci. 2008, 65, 1462-1468. [CrossRef] 
34. Gorelli, G.; Blanco, M.; Sardà, F.; Carretón, M.; Company, J.B. Spatio-temporal variability of discards in the fishery of the deep-sea red shrimp Aristeus antennatus in the northwestern Mediterranean Sea: Implications for management. Sci. Mar. 2016, 80, 79-88. [CrossRef]

35. Jennings, S. Indicators to support an ecosystem approach to fisheries. Fish Fish. 2005, 6, 212-232. [CrossRef] 